Doi: 10.5212/Publ.Exatas.v.15i1.063072

\title{
AVALIAÇÃO DE UM SENSOR DE RESISTÊNCIA ELÉTRICA E SUA CORRELAÇÃO COM ATRIBUTOS DO SOLO VISANDO À APLICAÇÃO NA AGRICULTURA DE PRECISÃO
}

\section{EVALUATION OF A ELECTRICAL RESISTANCE SENSOR AND ITS CORRELATION WITH SOIL ATTRIBUTES TO APPLICATION IN PRECISION AGRICULTURE}

\author{
Victor George Celinski'; Célia Regina Lopes Zimback²; Tatiana Montes \\ Celinski $^{1}$
}

${ }^{1}$ Universidade Estadual de Ponta Grossa - UEPG Av: Carlos Cavalcante, 4.748, Campus Uvaranas 84030-900 - Ponta Grossa, PR, Brasil. <vgcelinski@uepg.br>/<tmontesc@uepg.br>. ${ }^{2}$ Universidade Estadual Paulista - FCA-UNESP Rua José Barbosa de Barros, n. 1780, Fazenda do Lageado, Caixa Postal 237. 18610-307 - Botucatu, SP, Brasil

E-mail: <czimback@fca.unesp.br>.

Recebido para publicação em 15/01/2009

Aceito para publicação em 07/04/2009

\begin{abstract}
RESUMO
A resistência elétrica do solo tem sido utilizada como uma das variáveis que se correlacionam com atributos do solo. O presente trabalho teve como objetivos avaliar um sensor de resistência elétrica de contato e verificar a correlação entre as leituras da resistência elétrica com as propriedades químicas do solo (pH, M. O., K, Ca, Mg, SB, CTC e V\%). Os dados foram submetidos às análises de correlação e geoestatística. Foram gerados os mapas de superfície de cada parâmetro do solo por meio da técnica de krigagem. A finalidade dos mapas foi a de auxiliar na análise das correlações entre as variáveis. O sensor de resistência elétrica foi capaz de medir as variações da resistência elétrica do solo. As medidas de resistência elétrica obtidas correlacionaram-se satisfatoriamente com os teores de cálcio, magnésio e soma de bases (SB), o que demonstrou a possibilidade de uso do sensor para controle da fertilidade do solo.
\end{abstract}

Palavras-chave: Agricultura de precisão. Resistência elétrica do solo. Geoestatística.

\footnotetext{
ABSTRACT

The electrical resistance of the soil have been used as variables that correlate with its characteristics. This study aimed at evaluates an electrical resistance 
sensor of contact and verify the correlation between the measurements of electrical resistance with chemical properties of the soil (pH, M.O., K, Ca, Mg, SB, CTC e $\mathrm{V} \%$ ). The data were submitted to the analysis of correlation and geostatistic. From the analysis maps were generated for each parameter of the soil surface through the kriging technique. The purpose of the maps was assisting in the analysis of the correlation between the data. The electrical resistance sensor was capable to measuring variation of the electrical resistance of the soil. The obtained measures satisfactorily correlated with the levels of calcium, magnesium and SB. This demonstrated the possibility to use a sensor to verify the soil fertility control.

Keywords: Precision agriculture. Electrical resistance of the soil. Geostatistic.

\section{Introdução}

Desde os primórdios do século XX, alguns pesquisadores procuravam desenvolver uma metodologia para que os produtores pudessem amostrar, testar e mapear os solos de forma simples e prática e que resultasse numa economia dos insumos aplicados. (GUERRA, 2006). Para Grego et al. (2006), a investigação de possíveis causas da variabilidade espacial encontrada nos resultados de produtividade das culturas tem sido atribuída aos fatores de solo, como as propriedades físicas e químicas. Entretanto, tais propriedades são obtidas por amostragens que, na maioria das vezes, exigem alta demanda de mão de obra, de tempo e de custo.

A condutividade elétrica do solo tem chamado a atenção principalmente por ser obtida através de métodos eficientes e rápidos, como pelos sensores de contato direto com o solo. Jabro et al. (2006) investigaram a variabilidade espacial da condutividade elétrica do solo por contato e verificaram que a condutividade elétrica tem potencial para ajudar os agricultores a definirem áreas de manejo.

Na pesquisa realizada por Nascimento et al. (2008), observou-se que a adição de fertilizantes ao solo modificou suas características de resistividade elétrica. Os resultados revelaram que a resistividade elétrica do solo mostrou-se capaz de diferenciar as regiões com adição de fertilizantes no solo. Lezzi (2008) testou a aplicabilidade do sensor de resistividade elétrica do solo em campo, obtendo resultados positivos.

Adamchuk et al. (2004) relataram que embora exista uma grande variedade de sensores do solo, a maioria deles envolve um dos seguintes métodos de medição: os sensores elétricos e eletromagnéticos (que medem a resistividade), a condutividade, e a capacitância ou a indutância elétrica, sendo afetadas pela composição do solo. A maioria dos sensores fornece um sinal de saída, que é afetado por mais de uma característica agronômica do solo.

Sensores elétricos e eletromagnéticos são instrumentos de medida baseados em circuitos elétricos e usados para definir a habilidade de determinados meios em conduzir ou acumular a carga elétrica. Se o solo for usado como tal meio, suas características físicas e químicas podem afetar o comportamento do circuito elétrico e, assim, os parâmetros elétricos podem ser medidos. Dessa forma, faz-se necessário o desenvolvimento de sensores que realizem determinações com maior rapidez e que possuam boa correlação com o método padrão.

O desenvolvimento tecnológico de sistemas eletrônicos e computacionais, a disponibilidade de sinais de satélite para indicar a posição geográfica para o uso do sistema de posicionamento global (GPS) e sistemas para aquisição de dados através de diversos tipos de sensores e equipamentos vêm forçando a agricultura convencional, que trata áreas cultivadas como unidades homogêneas ao adotar mudanças nas práticas utilizadas. A busca por esse novo meio de produção agrícola tem levado ao conceito de agricultura de precisão.

Para Molin et al. (2005), a agricultura de precisão preconiza que o manejo das lavouras pode ser melhor conduzido se a variabilidade espacial da produtividade e dos fatores a ela relacionados forem conhecidos. Esses fatores podem ser tratados localizadamente, ou as lavouras podem ser divididas em unidades de gerenciamento diferenciado. Além dos 
mapas de produtividade, outras investigações podem auxiliar na definição de unidades de gerenciamento diferenciado.

Estudos com o uso da condutividade elétrica do solo têm apontado seu potencial para a mensuração de fatores, como argila, conteúdo de água, teor de sais da solução do solo, entre outros. Segundo Andrade et al. (2005), a caracterização da variabilidade espacial é essencial para um entendimento melhor das inter-relações entre atributos do solo. Com um modelo de dependência espacial de variáveis do solo, a geoestatística possibilita a estimativa em pontos não amostrados, viabilizando o mapeamento e o zoneamento da variável. Esse procedimento pode auxiliar na melhor distribuição das parcelas e experimentos em campo, assim como o manejo mais racional da água, de fertilizantes e de defensivos agrícolas.

Conforme Rabah (2002), pela geoestatística podem-se estabelecer as mais diversas correlações entre as determinações de uma variável em diversos pontos geográficos de uma mesma área de estudo, possibilitando, com isso, a geração de um mapa dessa variável voltado à seleção de culturas a serem desenvolvidas ou aos seus tratos culturais. Até pouco tempo, esses estudos normalmente eram efetuados usando-se as ferramentas estatísticas convencionais aplicadas em condições de variabilidade espacial que, na maioria das vezes, não apresentavam exatidão, impedindo com isso um efetivo mapeamento da variável na região estudada.

O presente estudo teve como objetivos projetar um sensor de resistência elétrica, avaliar seu desempenho em campo e verificar a correlação entre as leituras de resistência elétrica com alguns atributos químicos do solo (pH, M. O., K, Ca, Mg, SB, CTC e $\mathrm{V} \%$ ). Para as análises dos dados foram utilizados os recursos da estatística clássica e da geoestatística.

\section{Material e métodos}

A coleta dos dados da pesquisa foi realizada em uma gleba da fazenda Capão da Onça, pertencente à Universidade Estadual de Ponta Grossa, localizada na região dos Campos Gerais, no município de Ponta Grossa, no estado do Paraná.. O clima da região, segundo Köeppen esta sob a tipologia climática Cfb (IAPAR, 2000). Cfb corresponde ao clima sempre úmido, quente temperado, sem estação seca definida e com geadas frequentes no inverno, com temperaturas médias de $22{ }^{\circ} \mathrm{C}$ no verão. A precipitação anual é em torno de $1.422 \mathrm{~mm}$ e a umidade relativa do ar de $75 \%$, em média. O sensor de resistência elétrica desenvolvido no estudo tem o princípio de funcionamento semelhante ao método dos dois eletrodos, conforme foi exposto por Pincelli (2004).

O processo de montagem do sensor seguiu seu desenvolvimento pela escolha de alternativas práticas e de baixo custo. Procurou-se, então, utilizar um material que fosse menos susceptível a deformações. Optou-se pelo uso de tubos de cobre e de PVC, com 2,2 cm de diâmetro, utilizado em sistemas de água quente residenciais. Foram realizados vários testes com diversas medidas dos eletrodos e do isolador. Verificou-se que o melhor resultado foi dimensionar o sensor com $5 \mathrm{~cm}$ de comprimento para cada eletrodo e também para o isolador, formando uma haste de 15 cm de comprimento e 2,2 cm de diâmetro para aplicação vertical no solo, com uma das extremidades com forma pontiaguda para facilitar a penetração no solo, confeccionada com material isolante de uma resina acrílica, como pode ser observado na Figura 1.

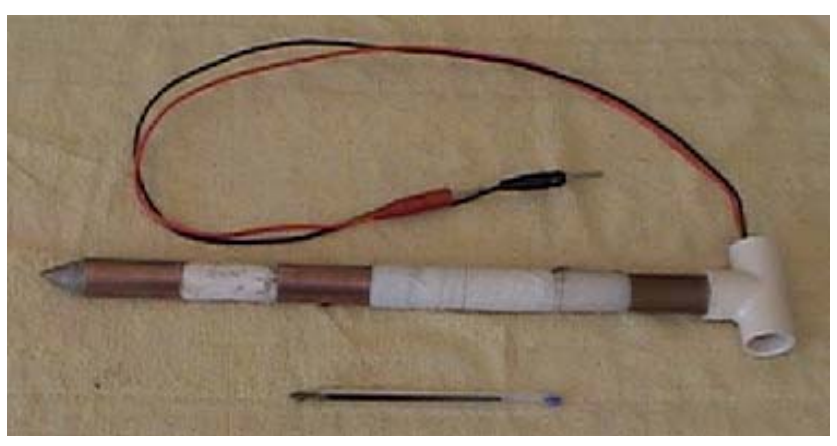

Figura 1 - Sensor de resistência elétrica.

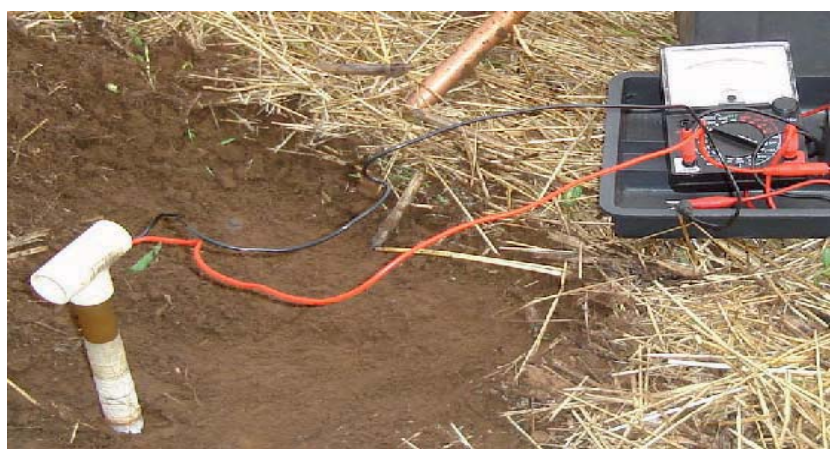

Figura 2 - Medição da resistência elétrica do solo com multímetro analógico. 
Para realizar as medidas de resistência elétrica do solo com o sensor em estudo, foi utilizado um multímetro analógico com ohmímetro, conforme a Figura 2. Esse método é semelhante ao utilizado por Rabello, Vaz e Torre Neto (2005), onde as medidas do sensor são obtidas por meio de um multímetro. O sensor foi introduzido verticalmente no solo até $20 \mathrm{~cm}$ de profundidade. Essa medida foi escolhida porque é nela que se situa a faixa onde a maior parte das raízes se concentra.

As medidas de resistência elétrica foram realizadas para cada ponto amostral antecedendo imediatamente a coleta das amostras do solo. Tal coleta foi realizada em uma área comercial de plantio direto com aproximadamente 13 hectares, totalizando 81 amostras, resultando em aproximadamente 6,2 leituras por hectare. Foi estabelecido um plano espacial determinado, mantendo uma regularidade na coleta de amostras por toda a área. As distâncias entre as amostras não foram iguais, mas a posição relativa de cada amostra foi georreferenciada com aparelho GPS portátil.

As amostras foram coletadas manualmente, com trado de $10 \mathrm{~cm}$ de diâmetro, na profundidade de 5 a $20 \mathrm{~cm}$, obedecendo a uma sequência sistemática em cada ponto de amostragem. Na profundidade de 0 a $5 \mathrm{~cm}$ não foram coletadas amostras, considerando que nesta profundidade o contato com o sensor seria prejudicado por apresentar-se deficiente. Foi observado que a colocação do sensor no solo aumenta em alguns milímetros o diâmetro de contato da superfície do solo com o sensor.

A análise química (macronutrientes) foi realizada nos laboratórios da Faculdade de Ciências Agronômicas da Universidade Estadual Paulista, campus de Botucatu. Para analisar a correlação das leituras de resistência elétrica medidas pelo sensor em relação aos atributos químicos, foram utilizados os resultados das amostras analisadas para determinar as características químicas de: potencial de hidrogênio (pH), matéria orgânica (M. O.), cálcio (Ca), magnésio (Mg), potássio (K), além dos seguintes parâmetros: soma de bases (SB), capacidade de troca de cátions (CTC) e saturação por bases (V\%).

As metodologias de determinação dos teores desses atributos do solo foram as mesmas utilizadas por Raij et al. (2001). Com a finalidade de verificar os valores de correlação dos atributos do solo em relação aos valores das medidas de resistência elétrica levan- tados em campo, foi realizada a análise de regressão com o gráfico da linha de tendência, apresentando a expressão matemática da relação e o coeficiente de determinação das variáveis. O coeficiente de determinação $\left(\mathrm{r}^{2}\right)$ é o índice que resulta a percentagem de variação de uma variável que é explicada estatisticamente pela variação na outra variável. Para o cálculo desses parâmetros foi utilizado o programa Microsoft Excel 2003.

Segundo Vanni (1998), o coeficiente de determinação pode ser interpretado pelo sentido relativo quando assumir valores entre 0 e 1 , revelando um percentual de ajustamento, onde um valor abaixo de 0,6 demonstra que a variável independente " $x$ " não explica com segurança a variação de "y”.

Para análise da distribuição dos pontos nos gráficos foi utilizada a metodologia conforme Doria Filho (1999), que classifica os coeficientes de correlação linear entre variáveis como perfeito, forte, médio, fraco e inexistente, de acordo com o índice da correlação.

O estudo da variabilidade espacial foi realizado por meio do software GS+ (Gamma Design Software, 2004), através da construção do semivariograma experimental e do ajuste do modelo matemático (semivariograma teórico), que proporcionou a menor soma dos quadrados dos resíduos (SQR). A partir do semivariograma teórico, foi gerado o mapa de contorno dos valores dos atributos do solo na área experimental por meio da técnica de krigagem, citado por Batista (2002) como o melhor método de interpolação para dados de atributos do solo.

A visualização dos resultados foi feita na forma de mapas bidimensionais, representativos da distribuição espacial dos valores dos atributos do solo em estudo, com o auxílio do programa Surfer versão 8.0 (Surface Mapping System), da Golden Software, Inc.

\section{Resultados e discussão}

O sensor do presente estudo resultou num sistema mecânico e eletrônico para a realização de sondagens dos atributos do solo no campo de maneira simples, rápida e de baixo custo. Sua principal vantagem é a de poder ser inserido no solo de forma vertical, como uma lança, e retirado com facilidade, proporcionando uma deformação mínima do solo (pequeno orifício de cerca de 2,2 cm de diâmetro). 
Os resultados da análise de regressão com o gráfico da linha de tendência, com a expressão matemática da relação e o coeficiente de determinação das variáveis podem ser visualizados nas Figuras 3 a 6 .

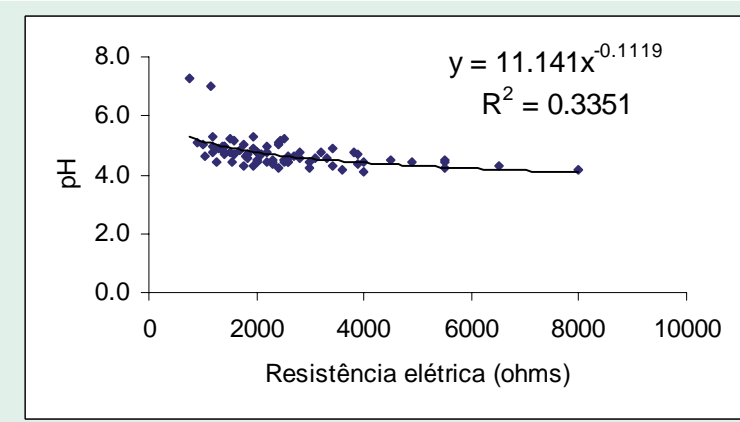

(a)

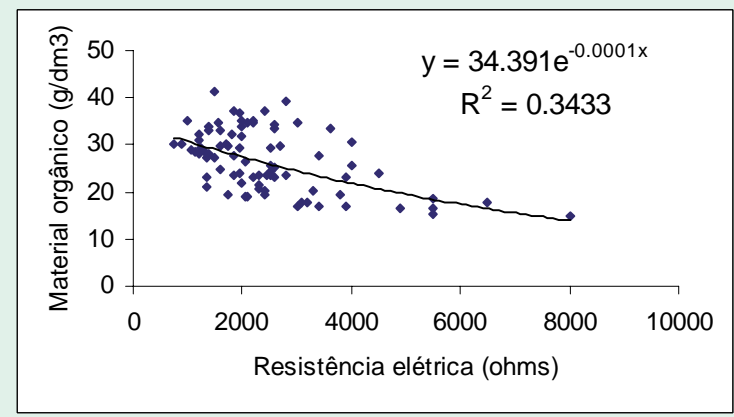

(b)

Figura 3 - Gráficos de regressão entre os valores de resistência elétrica com o pH (a) e com matéria orgânica (b).

Verifica-se na Figura 3 que os coeficientes de determinação dos gráficos, conforme Vanni (1998), não explicam com segurança as variações do índice de $\mathrm{pH}$. A variação do teor de material orgânico em função da resistência elétrica e a distribuição dos pontos nos gráficos se apresentam dispersas, indicando uma média correlação entre as variáveis, segundo a classificação adotada por Doria Filho (1999). Adotou-se para as demais análises dos coeficientes de determinação e dispersão dos dados a mesma metodologia utilizada na Figura 3, ou seja, coeficiente de determinação conforme Vanni (1998) e índice de correlação segundo Doria Filho (1999).

Analisando a Figura 4, nota-se que quanto maior o índice de material orgânico, menor o índice de resistência elétrica do solo, ou seja, maior a condutividade elétrica, se for obtido um resultado semelhante ao dos autores Benites e Mendonça (1998) e Oliveira et al. (2002), que verificaram em seus trabalhos que a elevação do teor de carbono orgânico gerou aumento na condutividade elétrica do solo.

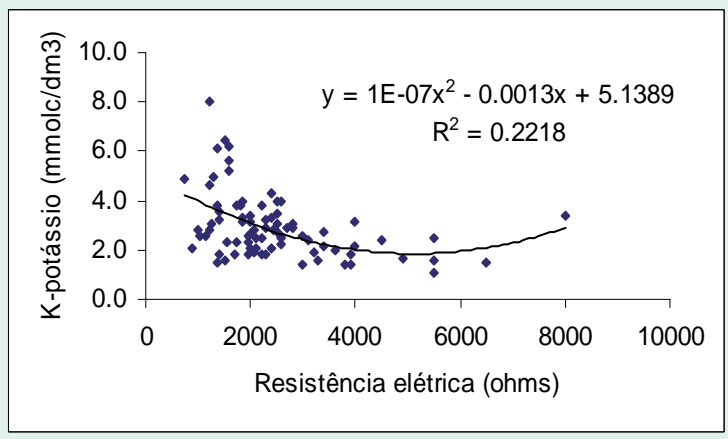

(a)

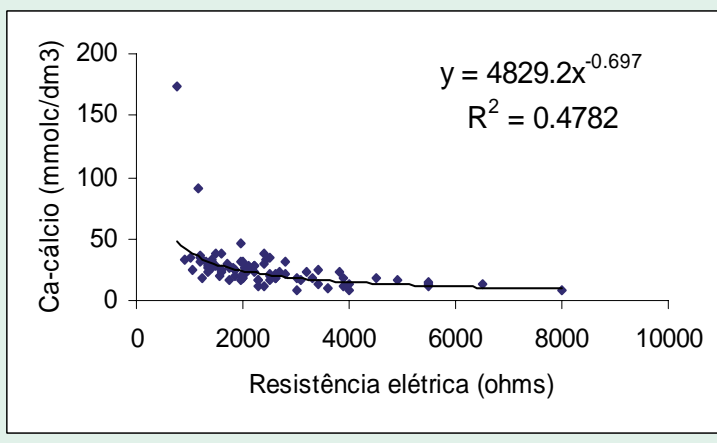

(b)

Figura 4 - Gráficos de regressão entre os valores de resistência elétrica com potássio (a) e com cálcio (b).

Pode-se verificar, na Figura 4 (a), que o coeficiente de determinação do gráfico não explica com segurança as variações do teor de potássio em função da resistência elétrica e a distribuição dos pontos no gráfico se apresenta muito dispersa, indicando uma fraca correlação entre as variáveis. Na Figura 4 (b), o coeficiente de determinação do gráfico também não explica com segurança as variações do índice de cálcio e a distribuição dos pontos no gráfico se apresenta dispersa, indicando uma média correlação entre as variáveis. 


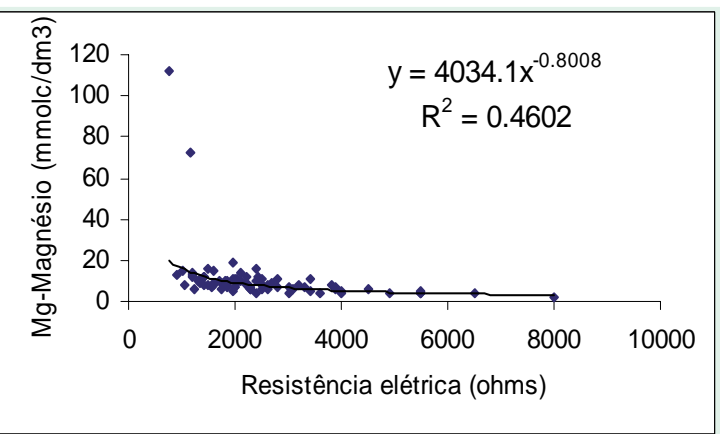

(a)

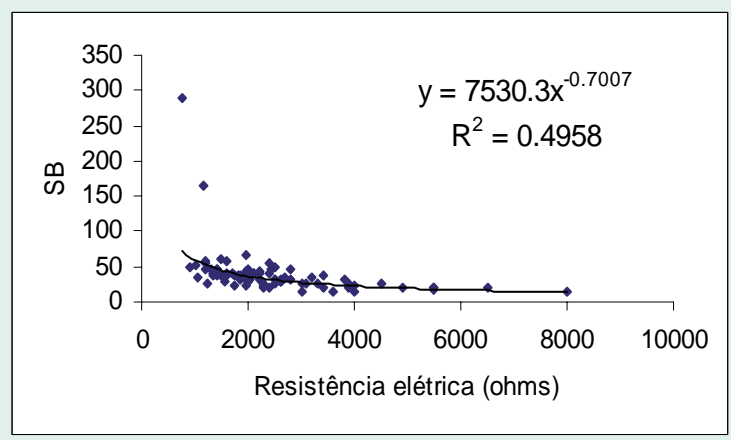

(b)

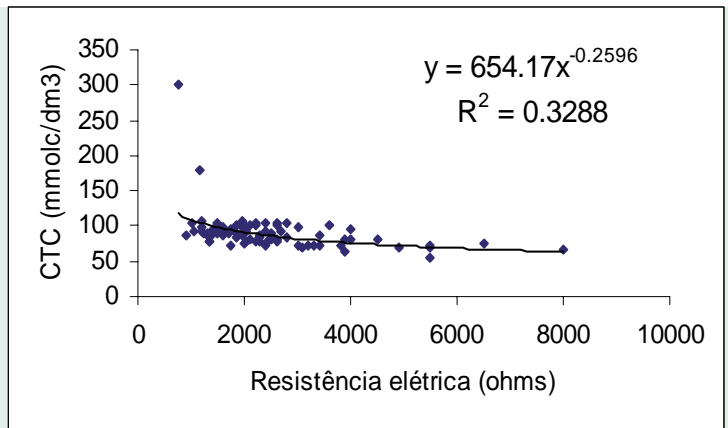

(a)

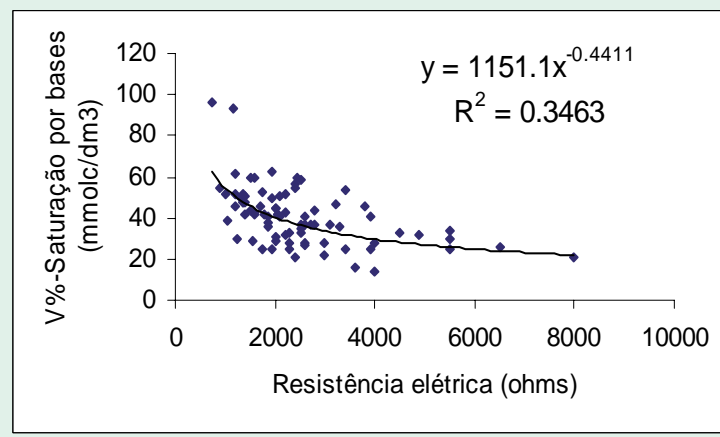

(b)
Figura 5 - Gráficos de regressão entre os valores de resistência elétrica com magnésio (a) e soma de bases (b).

Na Figura 5, os coeficientes de determinação dos gráficos não explicam com segurança as variações do índice de magnésio. A soma de bases e a distribuição dos pontos nos gráficos se apresentam dispersas, indicando uma média correlação entre as variáveis. Verificou-se, nos resultados apresentados nas Figuras 4 e 5, respectivamente, que quando se aumenta o valor dos teores de potássio, cálcio e magnésio o valor da resistência elétrica do solo se reduz.

Resultados semelhantes foram verificados por Caminha Junior, Seraphim e Gabriel (2000), onde baixos valores de resistividade elétrica foram justificados pelas altas concentrações de Ca, Mg e, principalmente, do potássio presente no solo.

Na Figura 6 pode-se visualizar que os coeficientes de determinação dos gráficos não explicam com segurança as variações do índice de CTC e V\% e a distribuição dos pontos nos gráficos se apresentam dispersos, indicando uma média correlação entre as variáveis.
Figura 6 - Gráficos de regressão entre os valores de resistência elétrica com CTC (a) e com V\% (b).

Utilizando os coeficientes de determinação gerados pelas análises de regressão, foram calculados os valores de correlação dos atributos do solo em relação às medidas de resistência elétrica do solo, conforme apresenta-se na Tabela 1.

Pode-se notar na Tabela 1 e nos respectivos gráficos de regressão que os melhores resultados de índices de correlação foram obtidos entre a resistência elétrica com relação aos atributos do solo, cálcio, magnésio e soma de bases que apresentaram seus índices bem próximos a uma forte correlação, segundo classificação de Doria Filho (1999).

Tabela 1 - Resultados dos coeficientes de correlação (r) entre os valores de resistência elétrica do solo e seus respectivos atributos.

\begin{tabular}{c|c|c|c|c|c|c|c|c} 
& M. O. & pH & Ca & Mg & SB & CTC & V\% & K \\
\hline $\mathbf{r}$ & 0,59 & 0,58 & 0,69 & 0,68 & 0,70 & 0,57 & 0,59 & 0,47 \\
\hline
\end{tabular}


A Tabela 2 apresenta os resultados das análises dos variogramas isotrópicos experimentais e teóricos para todas as variáveis em estudo amostradas em campo, indicando os valores do efeito pepita (Co), do patamar (Co + C1), do alcance (a), o índice de dependência espacial, classe de dependência espacial, o modelo de ajuste do variograma teórico ao experimental, o valor do coeficiente de determinação $\left(\mathrm{r}^{2}\right)$ e a soma dos quadrados dos resíduos (SQR).
$\mathrm{Na}$ análise de todos os atributos do solo da Tabela 2, verifica-se que, com exceção do potássio, que apresentou moderada dependência espacial, as demais variáveis apresentaram forte dependência espacial.

A Figura 7 apresenta a distribuição espacial das propriedades do solo estudadas para os valores de resistência elétrica, potássio, cálcio, CTC, magnésio, SB, pH e V\% do solo na área experimental.

Tabela 2 - Resultados das análises variográficas dos dados amostrados em campo.

\begin{tabular}{|c|c|c|c|c|c|c|c|c|}
\hline Variável & $\begin{array}{c}\text { Efeito } \\
\text { pepita } \\
\text { (Co) }\end{array}$ & $\begin{array}{c}\text { Patamar } \\
(\text { Co }+ \text { C1) }\end{array}$ & $\begin{array}{l}\text { Alcance } \\
\text { (a) (m) }\end{array}$ & $\begin{array}{c}{[\mathrm{C} 1 /(\mathrm{Co}+\mathrm{C} 1)]} \\
\times 100\end{array}$ & $\begin{array}{c}\text { Classe de } \\
\text { dependência } \\
\text { espacial }\end{array}$ & Modelo & $\mathbf{r}^{2}$ & SQR \\
\hline $\begin{array}{l}\text { Resistência } \\
\text { elétrica }\end{array}$ & 252000 & 1849000 & 236,9 & 86 & Forte & Esférico & 0,87 & $4,37 E+11$ \\
\hline $\mathrm{pH}$ & 0,054 & 1,127 & $*$ & 95 & Forte & Gaussiano & 0,85 & 0,0121 \\
\hline $\begin{array}{l}\text { Matéria } \\
\text { orgânica }\end{array}$ & 0,4 & 57,44 & 218 & 99 & Forte & Exponencial & 0,74 & 973 \\
\hline $\begin{array}{c}\mathrm{K}- \\
\text { Potássio }\end{array}$ & 0,925 & 1,851 & 105,5 & 50 & Moderada & Exponencial & 0,64 & 0,368 \\
\hline $\begin{array}{c}\mathrm{Ca}- \\
\text { Cálcio }\end{array}$ & 12 & 934,9 & * & 99 & Forte & Gaussiano & 0,65 & 208.343 \\
\hline $\begin{array}{c}\text { Mg - Mag- } \\
\text { nésio }\end{array}$ & 1 & 412,9 & * & 99 & Forte & Gaussiano & 0,69 & 44.281 \\
\hline SB & 1 & 3.112 & * & 99 & Forte & Gaussiano & 0,68 & $1,6 \mathrm{E}+06$ \\
\hline CTC & 8 & 2.126 & * & 99 & Forte & Gaussiano & 0,62 & $1,05 \mathrm{E}+06$ \\
\hline V\% & 92,7 & 380,4 & 1010,9 & 76 & Forte & Exponencial & 0,66 & 7.503 \\
\hline
\end{tabular}

*Não apresenta o valor do alcance definido. 


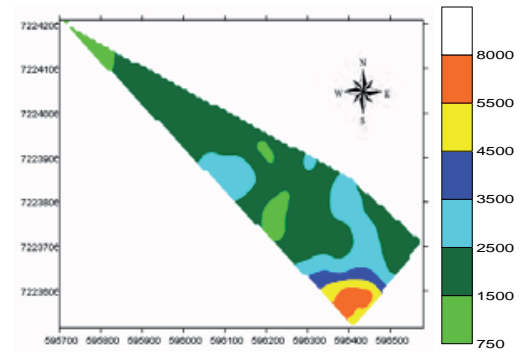

(a)

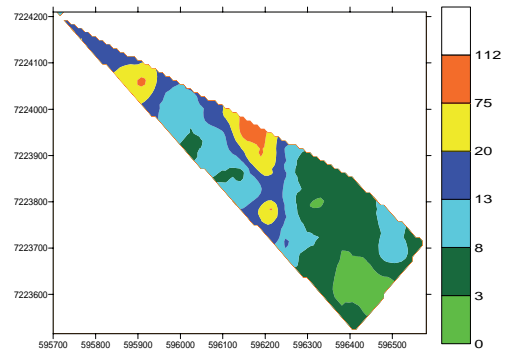

(b) $\left(\mathrm{mmol}_{\mathrm{c}} \cdot \mathrm{dm}^{-3}\right)$

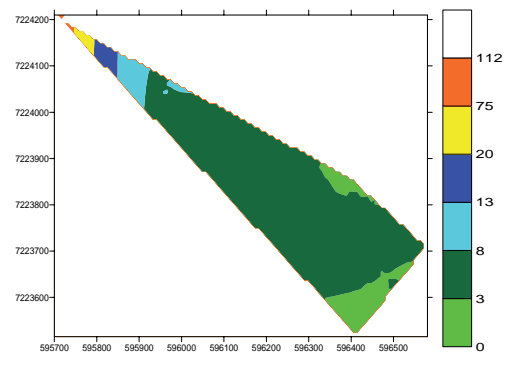

(c) $\left(\mathrm{mmol}_{\mathrm{c} \cdot \mathrm{dm}} \mathrm{d}^{-3}\right)$

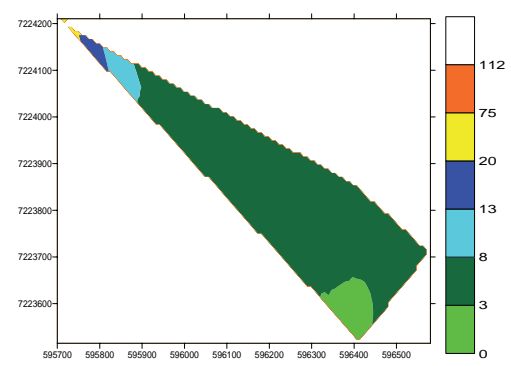

(d) $\left(\mathrm{mmol}_{\mathrm{c} \cdot} \cdot \mathrm{dm}^{-3}\right)$

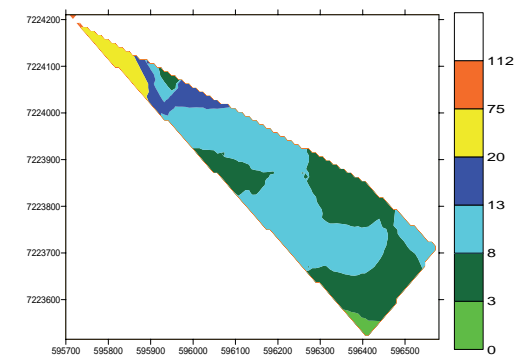

(e) $\quad\left(\mathrm{mmol}_{\left.\mathrm{c} \cdot \mathrm{dm}^{-3}\right)}\right.$

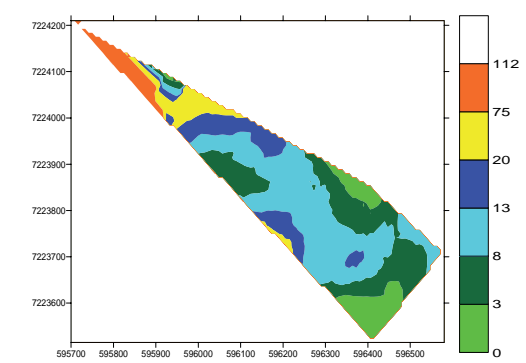

(f) $\quad\left(\mathrm{mmol}_{\mathrm{c} \cdot} \cdot \mathrm{dm}^{-3}\right)$

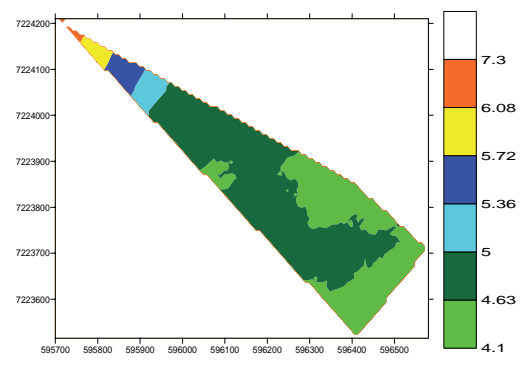

(g) (sem unidade)

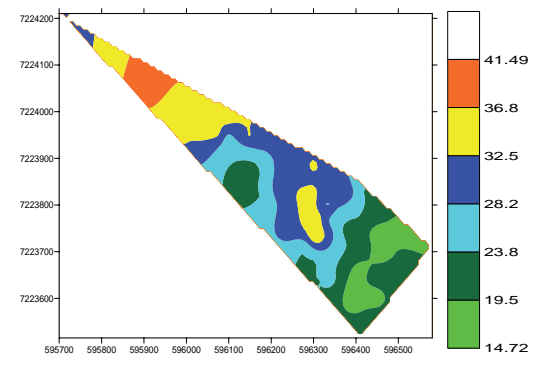

(h) $\quad\left(\right.$ g.dm $\left.{ }^{-3}\right)$

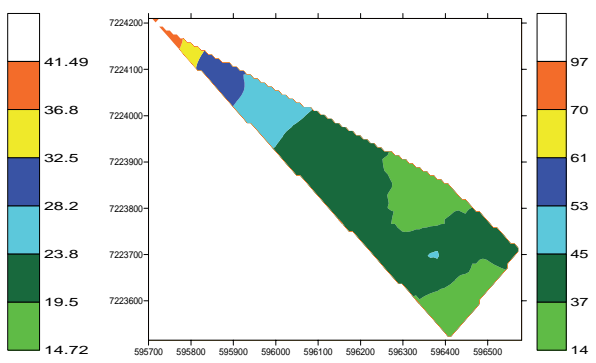

(i)

(\%)

Figura 7 - Mapas da variabilidade espacial dos níveis de resistência elétrica do solo (a), potássio (b), cálcio (c), CTC (d), magnésio (e), SB (f), pH (g), M. O. (h) e V\% (i).

Analisando-se os mapas, se observa que o mapa de resistência elétrica mostra visualmente maiores semelhanças com os mapas de magnésio (inversamente) e de soma de bases (inversamente). Observa-se, dos mapas, de forma visual conjunta, que quanto menor é o valor de resistência elétrica do solo, é maior o valor das demais variáveis: CTC, M. O., SB, Ca, Mg, V\%, pH e K.

Becegato (2005) também verificou em seu trabalho o que foi observado no presente estudo, ou seja, correlações negativas entre propriedades do solo e sua resistência elétrica, evidenciando que quanto maiores os teores das variáveis estudadas, maior é a facilidade com que a corrente elétrica transita pelo solo. 


\section{Conclusões}

O sistema desenvolvido apresentou um baixo custo e a metodologia utilizada para a coleta de dados foi satisfatória para as condições em que esta pesquisa foi realizada. O sensor apresentou capacidade para medir as variações da resistência elétrica do solo, correlacionando-se satisfatoriamente com os teores de cálcio, magnésio e soma de bases.

Os resultados verificados no presente estudo são promissores, pois demonstram que o sensor utilizado com o multímetro analógico para medir resistência elétrica do solo pode ser uma ferramenta útil no delineamento das unidades de gerenciamento e manejo localizado para os seguintes atributos do solo: cálcio, magnésio e soma de bases.

O estudo espacial das variáveis foi importante por mostrar que a distribuição espacial obedece praticamente aos mesmos padrões.

\section{Referências}

ADAMCHUK, V. I.; HUMMEL, J. W.; MORGAN, M. T.; UPADHYAYA, S. K. On -the-go soil sensors for precision agriculture. Computers and Electronics in Agriculture, v. 44, p. 71-91, 2004.

ANDRADE, A. R. S.; GUERRINI, I. A.; GARCIA, C. J. B.; KATEZ I.; GUERRA, H. O. C. Variabilidade espacial da densidade do solo sob manejo da irrigação. Ciência Agrotécnica, Lavras, v. 29, n. 2, p. 322-329, mar./abr., 2005.

BATISTA I. F. Variabilidade espacial da umidade do solo em irrigação por gotejamento sob cultivo protegido. 2002. 113f. Dissertação (Mestrado em Agronomia/ Irrigação e Drenagem) - Faculdade de Ciências Agronômicas, Universidade Estadual Paulista, Botucatu, 2002.

BECEGATO, V. A. Aplicação de técnicas geofísicas e geoquímicas em duas glebas agrícolas do noroeste do estado do Paraná e suas relações com fertilizantes fosfatados, 2005. Tese de doutorado. Universidade Federal do Paraná. Curitiba. 198p.

BENITES, V. M.; MENDONÇA, E. S. Propriedades eletroquímicas de um solo eletropositivo influenciadas pela adição de diferentes fontes de matéria orgânica. Revista Brasileira de Ciência do Solo, v.22, p.215-221, 1998.

CAMINHA JUNIOR, I. C.; SERAPHIM, O. J.; GABRIEL, L. R. A. Caracterização de uma área agrícola irrigada com efluente agroindustrial, através de análises químicas e da resistividade do solo. Energia na Agricultura, Botucatu, v.13, n.4, p.40-54, 2000.
DORIA FILHO, U. Introdução a bioestatística: para simples mortais. São Paulo: Negócio, 1999, 152p.

GREGO, C. R.; VIEIRA, S. R.; MOLIN, J. P.; MIGUEL, F. R. M.; PAVLU, F. A. Variabilidade espacial da condutividade elétrica do solo e da produtividade da mamona (Ricinus communis L.) no sistema de plantio direto. In: CONGRESSO BRASILEIRO DE AGRICULTURA DE PRECISÃO, 2. Anais... São Pedro, SP, 2006.

GUERRA, S. P. S. Desenvolvimento de um sistema informatizado de menor custo para aquisição e armazenamento de dados de sensores analógicos e receptor GPS. 2006. 118 f. Tese (Doutorado) - Faculdade de Ciências Agronômicas, Universidade Estadual Paulista, Botucatu, 2006.

IAPAR. Instituto Agronômico do Paraná. Cartas Climáticas do Estado do Paraná. Curitiba, 2000. Disponível em: http://200.201.27.14/Site/Sma/Cartas Climaticas/ CartasClimaticas.htm. Acesso em jul. 2007.

JABRO, J. D.; EVANS, R. G.; KIM, Y.; STEVENS, W. B.; IVERSEN, W. M. Characterization of spatial variability of soil electrical conductivity and cone index using coulter and penetrometer-type sensors. Soil Science, v. 171, n. 8, p. 627-637, 2006.

LEZZI, P. B. T. Teste de aplicabilidade de sonda de eletrorresistividade na avaliação de salinização secundária de solos. 2008. Dissertação (Mestrado) - Instituto de Geociências, Universidade de São Paulo, São Paulo, 2008.

MOLIN, J. P.; GIMENEZ, L. M.; PAULETTI, V.; SCHMIDHALTER, U.; HAMMER J. Mensuração da condutividade elétrica do solo por indução e sua correlação com fatores de produção. Engenharia Agrícola, Jaboticabal, v. 25, n. 2, p. 420-426, mai./ago. 2005.

NASCIMENTO, C. T. C.; FERREIRA, F. J. F.; ANDRADE, L. R. M.; GASPAR, J. C.; PIRES, A. C. B. Radiação gama e resistividade elétrica em solo com aplicação de carbonalito e fertilizantes agrícolas no Distrito Federal. Revista Brasileira de Geofísica, São Paulo, v. 26, n. 1, 2008.

OLIVEIRA, F. C.; MATTIAZZO, M. E.; MARCIANO, C. R.; ABREU JUNIOR, C. H. Alterações em atributos químicos de um Latossolo pela aplicação de composto de lixo urbano. Pesquisa Agropecuária Brasileira, v.37, p.529-538, 2002.

PINCELLI, A. L. S. Desenvolvimento e ensaios de um sistema de mensuração de condutividade elétrica do solo. 2004. 96 f. Dissertação (Mestrado em Agronomia) - Escola Superior de Agricultura Luiz de Queiroz, Universidade de São Paulo, Piracicaba, 2004.

RABAH, F. A. Dependência especial de atributos do solo obtidos por meio de variogramas e autocorrelogramas. 2002. Tese ( Doutorado em Agronomia) - Faculdade de Ciências Agronômicas, Universidade Estadual Paulista, Botucatu, 2002. 
RABELLO, L. M.; VAZ, C. M. P.; TORRE NETO, A. Sensor capacitivo para sondagem da umidade no perfil de solo. Comunicado Técnico, 71, Embrapa Instrumentação Agropecuária, São Carlos, SP, novembro. 2005.

RAIJ, B. van.; ANDRADE, J.C.de.; CATARELLA, H.; QUAGGIO, J.A. Análise química para avaliação de fertilidade de solos tropicais. Campinas: Instituto Agronômico, 2001. $285 \mathrm{p}$.

VANNI, S. M. Modelos de regressão: estatística aplicada. São Paulo: Legmar Informática e Editora, 1998. 177p. 